Tropical Journal of Pharmaceutical Research October 2019; 18 (10): 2139-2145

ISSN: 1596-5996 (print); 1596-9827 (electronic)

(1) Pharmacotherapy Group, Faculty of Pharmacy, University of Benin, Benin City, 300001 Nigeria.

\title{
Development of HPTLC method for determination of $\alpha$ - terpinyl acetate, and evaluation of antioxidant properties of essential oils in Elettaria cardamomum
}

\author{
Aftab Alam, Rita Singh Majumdar, Pravej Alam \\ ${ }^{1}$ Department of Biotechnology, School of Engineering, Sharda University, Greater Noida, UP, India, ${ }^{2}$ Department of Biology, \\ College of Science and Humanities, Prince Sattam bin Abdulaziz University, Saudi Arabia
}

*For correspondence: Email: aftab.sharda@gmail.com

\begin{abstract}
Purpose: To develop a simple and reliable protocol for high performance thin layer chromatography (HPTLC) quantification of a-terpinyl acetate in oils extracted from Elettaria cardamomum, and to study relative antioxidant potential of oils obtained from three varieties of fruits of $E$. cardamomum.

Methods: Essential oil was extracted separately from the fruits of three varieties of E. cardamomum, viz, Valley-green, Palakuzhi, and ICRI-2, using hydro-distillation method. In the development of an HPTLC method, standard a-terpinyl acetate was subjected to chromatography on aluminium-backed silica gel $60 F_{254}$ plates using a mobile phase of $n$-hexane: ethyl acetate (8:2, v/v), and quantified at 665 $\mathrm{nm}$ through densitometric analysis. The antioxidant property of essential oil of each cultivar was determined with respect to 2,2-diphenyl-1-picrylhydrazyl (DPPH) and 2,2'-azino-bis(3ethylbenzothiazoline-6-sulphonic acid (ABTS) radical scavenging assays, as well as ferric reducing assay.

Results: The developed HPTLC method showed a good resolution for $\alpha$-terpinyl acetate, with $R_{f}$ of 0.64 \pm 0.01 , and also showed good linearity of the calibration plots $\left(r^{2}=0.9982\right)$. The HPTLC method was validated as per ICH guidelines, and used for the determination of $\alpha$-terpinyl acetate in the essential oils. The valley green variety of $E$. cardamomum had the highest content of $\alpha$-terpinyl acetate $(55.36 \pm 1.33$ $\% W / W$ ). The inhibitory capacity $\left(I C_{50}\right.$ value) for the oil of valley green variety as determined using DPPH and ABTS methods was 378.2 and $19.87 \mu \mathrm{g} / \mathrm{mL}$, respectively.

Conclusion: The proposed HPTLC method is suitable for routine analysis of a-terpinyl acetate in medicinal herbs, and it reveals the role of $\alpha$-terpinyl acetate in the antioxidant efficacy of cardamom oil.
\end{abstract}

Keywords: HPTLC, $\alpha$-Terpinyl acetate, Elettaria cardamomum, Cardamom oil, Antioxidant

This is an Open Access article that uses a fund-ing model which does not charge readers or their institutions for access and distributed under the terms of the Creative Commons Attribution License (http://creativecommons.org/licenses/by/4.0) and the Budapest Open Access Initiative (http://www.budapestopenaccessinitiative.org/read), which permit unrestricted use, distribution, and reproduction in any medium, provided the original work is properly credited.

Tropical Journal of Pharmaceutical Research is indexed by Science Citation Index (SciSearch), Scopus, International Pharmaceutical Abstract, Chemical Abstracts, Embase, Index Copernicus, EBSCO, African Index Medicus, JournalSeek, Journal Citation Reports/Science Edition, Directory of Open Access Journals (DOAJ), African Journal Online, Bioline International, Open-J-Gate and Pharmacy Abstracts

\section{INTRODUCTION}

Elettaria cardamomum (Maton), popularly known as Indian green cardamom, is native to South East Asia. The fruits and seeds of this plant are sources of very famous and expensive spices all over the world, and they have multiple health benefits. They are used as flavouring agents, food additives and constituents of several aromatic flavours [1]. The anti-inflammatory, 
antimicrobial, and antioxidant properties of essential oil of the fruits of cardamom have been previously reported [2,3]. The essential oil and extract of cardamom fruits are also used for treatment of several ailments in the conventional and alternative system of medicine [3]. The natural cultivars of the plant (Mysore, Malabar, and Vazhukka) are cultivated in the southern parts of India [4]. Several varieties of green cardamom have been developed by ICRI-India through breeding technology. These include high-yielding varieties such as Vazhukka (valley green), Malabar (Palakuzhi) and Mysore (ICRI-2) cultivars [4-6].

Alpha-terpinyl acetate, an essential oil related the terpenoid family, contributes to the flavour and fragrance of E. cardamomum fruits [7]. Alcohol extract of the seeds or fruits has been previously reported to have several medicinal values such as gastrointestinal protection, as well as antiinflammatory, analgesic, antimicrobial, antiviral, hypotensive, antispasmodic, mucolytic and antioxidant effects [8,9]. High performance thin layer chromatography (HPTLC) is one of the cost-effective and rapid chromatographic techniques used for quantification of secondary metabolites in the plants and plant parts, and for detection of complex mixtures of drugs, natural products, essential oils and foodstuffs [10].

Worldwide, there is growing demand for natural antioxidants. The essential oil of fruits of $E$. cardamomum might be an alternative source of antioxidant medicine [11]. There are several varieties of $E$. cardamomum which have $\alpha$ terpinyl acetate as a major bioactive constituent, but due to the low concentration of a-terpinyl acetate, their antioxidant potential are not satisfactory.

The aim of the current study was to develop a reliable HPTLC protocol for the quantification of a-terpinyl acetate and screening of $E$. cardamonum cultivars for contents of $\alpha$-terpinyl acetate. Furthermore, the antioxidant potential of a-terpinyl acetate was evaluated using comparative study of oils from selected cultivars of the plant to confirm the contribution of this compound to the antioxidant effect.

\section{EXPERIMENTAL}

\section{Materials}

Dried fruits of valley green, Palakuzhi and ICRI-2 cultivars of the plant were procured from ICRI, Myladumpara, Idukki, and Kerala, India. Authentication reference (ICRI RES-500), voucher number and invoice reference number-
27414) were provided by ICRI purchase department. The reagents ABTS and DPPH, and standard BHT, $\alpha$ - terpinyl acetate (purity $\geq 95 \%$ ) were procured from Sigma Aldrich, USA). The solvents used in the chromatography and antioxidant activity were of $A R$ grade.

\section{Instrumentation}

Aluminium-baked pre-coated TLC plates (silica

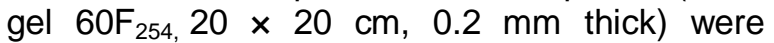
obtained from E. Merck. Camag-Automatic TLC Sampler-4, automatic development chamber (ADC2), Camag UV cabinet-4, Camagderivatization chamber, Camag-TLC plate heater and Camag-TLC Reprostar 3 were the main instruments used in this study.

\section{Isolation of cardamom essential oil}

The dried fruits $(70 \mathrm{~g})$ of each variety were ground to a coarse powder, and essential oils were extracted through hydro-distillation for $4 \mathrm{~h}$ using Clevenger-type apparatus. The water moiety of the extracts was slowly drawn off using the anhydrous $\mathrm{Na}_{2} \mathrm{SO}_{4}$, and the resultant oil extract was collected in an amber-coloured bottle and preserved at $4^{\circ} \mathrm{C}$ for use in subsequent studies.

\section{Instrumentation conditions used for development of the HPTLC method}

Chromatography was executed on TLC plates $(20 \mathrm{~cm} \times 10 \mathrm{~cm})$. Samples were applied using TLC Sampler-4 applicator. Several mobile phases containing hexane, toluene, benzene, ethyl acetate, chloroform and methanol in different proportions, or ethanol alone were tried. Finally, a mixture of hexane: ethyl acetate (8: 2; $\mathrm{v} / \mathrm{v}$ ) was found to be the most appropriate for $\alpha$ terpinyl acetate studies. The mean retention factor (Rf) value of $\alpha$-terpinyl acetate was $0.64 \pm$ 0.01 . The mobile phase (hexane: ethyl acetate (8: 2, v: v; $20 \mathrm{~mL}$ ) was placed in the twin-trough glass chamber and saturated for $5 \mathrm{~min}$ at room temperature $\left(25 \pm 5^{\circ} \mathrm{C}\right)$ and relative humidity of $60 \pm 2 \%$. Linear ascending development was performed, and thereafter, the plates were airdried and screened in UV chamber under low-UV (254 nm), high-UV (366 nm) and white light. The plates were derivatized using anisaldehydesulfuric acid reagent, and heated up to $100{ }^{\circ} \mathrm{C}$ using plate heater. The plates were then cooled and scanned at $665 \mathrm{~nm}$ using -TLC scanner in absorbance mode. The results were calculated using WinCats software. 


\section{Preparation of standard solution of $\alpha$ - terpinyl acetate and calibration curve}

$\alpha$-Terpinyl acetate $(10 \mathrm{mg})$ was transferred into a volumetric flask $(10 \mathrm{~mL})$, mixed with methanol (5 $\mathrm{mL}$ ) and sonicated for $10 \mathrm{~min}$. Then, the volume was made up to the mark with methanol. Different dilutions of standard $\alpha$-terpinyl acetate were prepared and used for preparation of standard calibration curve. The regression equation, correlation coefficient, slope and intercept of the curves were calculated from the standard plot.

\section{Preparation of sample solution}

Exactly $20.0 \mathrm{mg}$ of essential oil of each variety of E. cardamomum (Valley green, Palakuzhi, and ICRI-2) was transferred to $10 \mathrm{~mL}$ volumetric flask; $5 \mathrm{~mL}$ methanol was added, and the solution was sonicated for $10 \mathrm{~min}$. Then, the volume was made up to the mark with methanol.

\section{Method validation}

The developed method was validated for accuracy, specificity, sensitivity, precision, and robustness, as per ICH guidelines [12].

\section{Specificity and sensitivity}

The specificity and sensitivity of the HPTLC method were assessed by analysing sample solutions with $\alpha$-terpinyl acetate and $E$. cardamomum essential oil subjected to interferences from oils and other compositions. The sample spot was matched with $R f$ values of the spot of the standard $\alpha$-terpinyl acetate. The limit of quantification (LOQ) and the limit of detection (LOD) were used to measure the sensitivity of the developed method.

The LOQ and LOD were calculated using Equations 1 and 2 below:

$L O D=3 a / S)$

$L O Q=103 a / S$

where $a$ is standard deviation of $y$-intercepts, and $S$ is the slope of the developed calibration curve.

\section{Accuracy}

Accuracy was expressed as \% recovery. The measurements were performed by addition of $\alpha$ terpinyl acetate solution at four different levels $(0$, 50,100 and $150 \%$ ) to a pre-analysed sample solution (300 ng/band). All the experiments were performed in triplicate $(n=3)$.

\section{Precision and robustness}

Precision studies were performed to determine the repeatability and reproducibility of the new method. Intra-day precision was determined by analysing standard solutions ((300, 400 and 500 $\mathrm{ng} / \mathrm{spot})$ on the same day, while inter-day precision was determined by analysing on three consecutive days. The robustness of the method was aimed at determining the effect of small changes in the ratio of the solvent system, distance development, and chamber saturation time on $R_{\mathrm{f}}$ value and peak area of $\alpha$ - terpinyl acetate.

\section{Determination of antioxidant potential}

\section{DPPH free radical scavenging assay}

In the present study, the DPPH free radical scavenging effect was determined using an earlier method, with slight modifications [13]. Stock solutions of the essential oil of each variety and the standard solutions were prepared in methanol. Stock solutions of different dilutions (1000 to $10 \mu \mathrm{g} / \mathrm{mL}$ ) were made to assess the antioxidant property of the oils. One millilitre of a diluted solution of each sample or standard was separately mixed with DPPH $(90 \mu \mathrm{M}$, in methanol) and the volume was made up to $4 \mathrm{~mL}$ using methanol. The absorbance of the diluted samples and standard were read in a spectrophotometer at $517 \mathrm{~nm}$, and the $\mathrm{IC}_{50}$ of each essential oil was calculated.

\section{ABTS free radical scavenging assay}

The radical scavenging of ABTS was based on an earlier method with slight modification [14]. Briefly, dilutions (15 - $45 \mu \mathrm{g} / \mathrm{mL}$ ) of the stock solution of standard and samples were prepared. The working solution of ABTS was prepared using ABTS (7 mM) and potassium persulfate (2.45 $\mathrm{mM}$; 1:1 v: v), and the solution was kept in the dark for $4 \mathrm{~h}$ at $25^{\circ} \mathrm{C}$. The working solution was mixed with phosphate buffer to get an absorbance of $0.70 \pm 0.02$ at $734 \mathrm{~nm}$ before use. Then, $3 \mathrm{~mL}$ of standard or sample was added to $1 \mathrm{~mL}$ of working solution. The absorbance of the diluted samples and standard were read in a spectrophotometer, and $\mathrm{IC}_{50}$ value of each essential oil was calculated.

\section{Ferric chloride reducing (FR) power assay}

The assessment of FR assay was based on an earlier method of Han et al, with slight modifications [15]. A stock solution was diluted serially $(0.25$ to $10 \mathrm{mg} / \mathrm{ml})$. Then, $1 \mathrm{ml}$ of sample solution, phosphate buffer $(2.5 \mathrm{~mL} ; 0.2 \mathrm{~mol} / \mathrm{L}, \mathrm{pH}$ 
6.6), and potassium ferricyanide (2.5 mL, $1 \%)$ were mixed and incubated for $30 \mathrm{~min}$ at $50^{\circ} \mathrm{C}$. Trichloroacetic acid solution (10\%, $2.5 \mathrm{ml})$ was added, followed by centrifugation at $10,000 \mathrm{rpm}$ for $10 \mathrm{~min}$. Thereafter, $2.5 \mathrm{ml}$ of the supernatant was added to $2.5 \mathrm{~mL}$ of distilled water and 0.5 $\mathrm{mL}$ of $0.1 \% \mathrm{FeCl}_{3}$ solution. The absorbance of the diluted samples and standard were read at $700 \mathrm{~nm}$ in a spectrophotometer.

\section{Statistical analysis}

Data are expressed as mean $\pm(S D)$. The $I C_{50}$ values were calculated using non-linear regression, followed by log inhibitor vs. response variable slope, using Graph-Pad Prism version 7.03 .

\section{RESULTS}

The mixture of mobile phase, hexane: ethyl acetate (8: 2; v/v) gave good resolution with $\mathrm{R}_{\mathrm{f}}$ value of 0.64 . The thin layer chromatography chamber was saturated for $10 \mathrm{~min}$. The band of TLC plates was visualized after derivatization with spray reagents at $665 \mathrm{~nm}$. The identification of $\alpha$ - terpinyl acetate in the essential oil was confirmed by matching with the chromatogram of standard $\alpha$ - terpinyl acetate. Figure 1 shows the densitogram of the developed HPTLC method for standard $\alpha$ - terpinyl acetate.

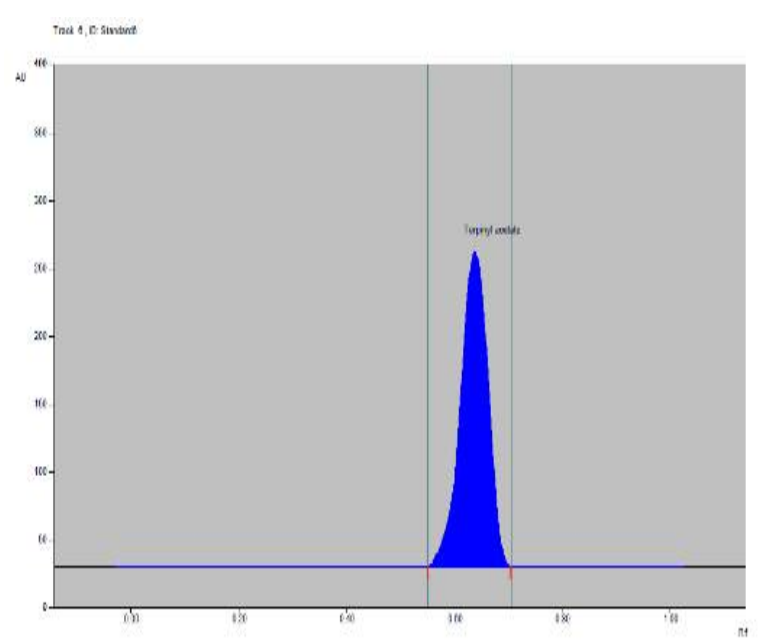

Figure 1: Chromatogram of standard a-terpinyl acetate: peak of $300 \mathrm{ng}\left(\mathrm{R}_{\mathrm{f}}=0.64\right)$

The peak area of each concentration $(100,200$, $300,400,500,600$ and $700 \mathrm{ng} / \mathrm{band}$ ) of $\alpha$ terpinyl acetate was calculated, and a graph of standard solution versus peak area was plotted. The calibration curve for $\alpha$-terpinyl acetate has good linearity with a correlation coefficient of is shown in Figure 2.

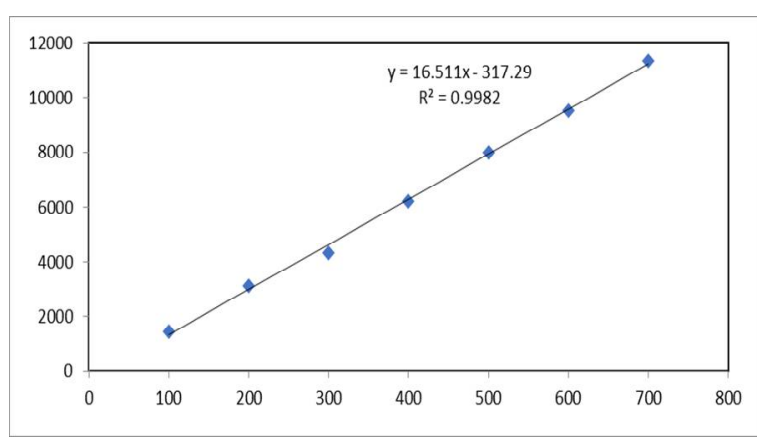

Figure 2: Standard calibration curve of a-terpinyl acetate at different concentrations of a-terpinyl acetate (100 - $700 \mathrm{ng} / \mathrm{band})$

The regression equation, correlation coefficient, slope, intercept LOD and LOQ of the a-terpinyl acetate were $y=16.5 x-317.29,0.9982,16.5 \pm$ $0.3178, \quad 317 \pm 142.1, \quad 6.20$, and 17.12, respectively. Linearity was found in the range of $100-700 \mathrm{ng} /$ band as shown in Table 1.

Table 1: Calibration parameters of standard $\alpha$-terpinyl acetate

\begin{tabular}{lr}
\hline Parameter & $\begin{array}{r}\boldsymbol{\alpha} \text {-Terpinyl } \\
\text { acetate }(\mathbf{n}=6)\end{array}$ \\
\hline Linearity (ng/spot) range & $100-700$ \\
Equation of regression & $Y=16.5 x-317.29$ \\
Correlation coefficient & 0.9982 \\
Slope \pm SE & $16.5 \pm 0.3178$ \\
Intercept \pm SE & $317 \pm 142.1$ \\
Cl (95\%) of slope & 15.69 to 17.32 \\
Cl (95\%) of intercept & 679.3 to 51.43 \\
$F$ value & 2696 \\
DF (nominator per denominator) & 1.49 \\
(DFn/DFd) & $<0.0001$ \\
$P$ value & 6.20 \\
LOD (ng/band) & 17.12 \\
LOQ (ng/band) &
\end{tabular}

The accuracy of the method was analysed in the triplicate mode. The effects of recovery were calculated in terms of percentage recovery (\%) and the results are shown in Table 2. The recovery of $\alpha$-terpinyl acetate was in the range of $97.75-99.38 \%$.

The range of RSD for intraday (repeatability) precision was $0.28-0.61 \%$. Inter-day precision study was performed using measurement of peak area for three consecutive days. The range of RSD for interlay (intermediate) precision was $0.39-0.71 \%$ (Table 3).

The range of RSD obtained for robustness of method was $0.51-0.59 \%$, after introducing small changes in the developed method. The results are shown in Table 4. 
Table 2: Accuracy of the HPTLC method standard for determination of $\alpha$-terpinyl acetate

\begin{tabular}{lcccc}
\hline $\begin{array}{l}\text { Excess } \alpha \text {-terpinyl acetate } \\
\text { added to analyte (\%) }\end{array}$ & Content $(\mathbf{n g})$ & \multicolumn{3}{c}{$\boldsymbol{\alpha}$-Terpinyl acetate } \\
\cline { 3 - 5 } & & Conc \pm SD (ng) & $\begin{array}{c}\text { Recovery } \\
\text { (\%) }\end{array}$ & $\boldsymbol{R S D ( \% )}$ \\
\hline 0 & 200 & $195.50 \pm 2.52$ & 97.75 & 0.79 \\
50 & 300 & $291.50 \pm 1.76$ & 97.20 & 0.94 \\
100 & 400 & $398.50 \pm 0.84$ & 99.38 & 0.21 \\
150 & 500 & $493.50 \pm 1.64$ & 98.63 & 0.85 \\
\hline
\end{tabular}

Table 3: Inter-day and intra-day precision

\begin{tabular}{|c|c|c|c|c|}
\hline \multirow{2}{*}{$\begin{array}{l}\text { (Conc. } \\
\text { (g/spot) }\end{array}$} & \multirow[b]{2}{*}{ Precision } & \multicolumn{3}{|c|}{$\alpha$-Terpinyl acetate } \\
\hline & & $\begin{array}{c}\text { Mean conc. } \pm S D \\
(n=6)\end{array}$ & $\begin{array}{c}\text { SE (Standard } \\
\text { Error) }\end{array}$ & $R S D(\%)$ \\
\hline 300 & Repeatability precision & $4335.00 \pm 26.36$ & 10.36 & 0.61 \\
\hline 400 & (intra-day) & $6219.00 \pm 31.68$ & 12.93 & 0.51 \\
\hline 500 & & $7998.80 \pm 22.11$ & 9.03 & 0.28 \\
\hline 300 & Intermediate precision & $4333.00 \pm 30.80$ & 12.57 & 0.71 \\
\hline 400 & (inter-day) & $6221.00 \pm 36.72$ & 15.00 & 0.59 \\
\hline 500 & & $8006.80 \pm 31.38$ & 12.81 & 0.39 \\
\hline
\end{tabular}

Table 4: Robustness of the new HPTLC method

\begin{tabular}{lcccccc}
\hline $\begin{array}{l}\text { Conc } \\
\text { (ng/spot) }\end{array}$ & Original $^{*}$ & $\begin{array}{c}\text { Solvent } \\
\text { system }\end{array}$ & Change & \multicolumn{2}{c}{$\alpha$-Terpinyl acetate } \\
& & & & Area $\pm \boldsymbol{S} \boldsymbol{D},(\boldsymbol{n}=3)$ & $\boldsymbol{R}_{\boldsymbol{f}}$ & $\% \boldsymbol{R S D}$ \\
400 & & $7.9: 2.1$ & $-0.1,+0.1$ & $6241 \pm 37$ & 0.66 & 0.59 \\
& $8: 2$ & $8: 2$ & 0.0 & $6219 \pm 32$ & 0.64 & 0.51 \\
& & $8.1: 1.9$ & $+0.1,-0.1$ & $6217 \pm 35$ & 0.62 & 0.56 \\
\hline
\end{tabular}

*Mobile phase (Hexane: ethyl acetate)

Table 5: Percentage of $\alpha$-terpinyl acetate in the three varieties of essential oils $(n=3)$.

\begin{tabular}{lc}
\hline Essential oil & $\begin{array}{c}\text { Content (mean } \pm \text { SD, } \% \\
\text { w/w of oil) } \\
\text { a-terpinyl acetate }\end{array}$ \\
\hline Valley green & $55.36 \pm 1.33$ \\
Palakuzhi & $41.82 \pm 4.11$ \\
ICRI-2 & $41.42 \pm 2.17$ \\
\hline
\end{tabular}

\section{Antioxidant potential of essential oils}

The scavenging power in terms of $\mathrm{IC}_{50}$ (using DPPH and ABTS methods) for Valley green, Palakuzhi and ICRI-2 varieties of $E$. cardamomum and BHT (standard) are shown in Table 6. In the DPPH method, the essential oil obtained from Valley green had the highest antioxidant potential $\left(\mathrm{IC}_{50}=378.2 \mu \mathrm{g} / \mathrm{mL}\right)$, followed by Palakuzhi $\left(\mathrm{IC}_{50}=485.4 \mu \mathrm{g} / \mathrm{mL}\right)$ and ICRI-2 $\left(I_{50}=547.7 \mu \mathrm{g} / \mathrm{mL}\right)$. In the ABTS free radical scavenging assay, the essential oil of Valley green also had higher antioxidant potential $\left(\mathrm{IC}_{50}=19.87 \mu \mathrm{g} / \mathrm{mL}\right)$ than any of the other two varieties.

The results of ferric reducing power for the three essential oils are shown Figure 3 . The reducing power was in the increasing order of $\mathrm{BHT}>$ Valley green $>$ Palakuzhi $>$ ICRI-2.
Table 6: $\mathrm{IC}_{50}(\mu \mathrm{g} / \mathrm{mL})$ values of the essential oils of three varieties of $E$. cardamomum $(\mathrm{n}=3)$

\begin{tabular}{lll}
\hline Essential oil & DPPH & ABTS \\
\hline Valley green & 378.2 & 19.87 \\
Palakuzhi & 485.4 & 20.2 \\
ICRI-2 & 547.7 & 23.09 \\
BHT & 81.47 & 19.8 \\
\hline
\end{tabular}

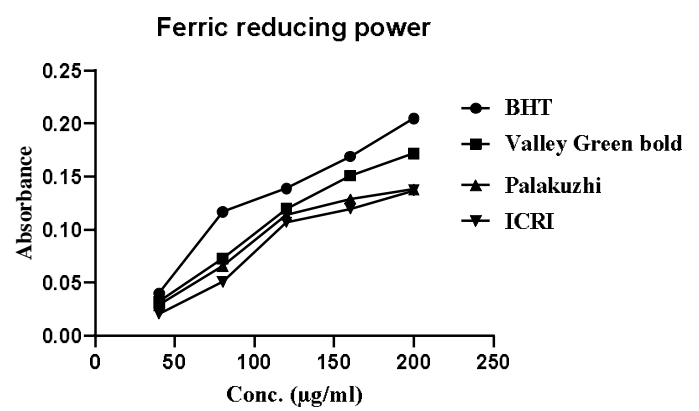

Figure 3: Ferric reducing power of the oils of varieties of $E$. cardamomum, and BHT standard. Values are presented as mean $\pm \operatorname{SD}(n=3)$.

\section{DISCUSSION}

The proposed HPTLC procedure was optimized with a view to quantifying the presence of $\alpha$ terpinyl acetate in the essential oils. The method was validated using $\mathrm{ICH}$ guidelines [12]. The solvent mixture of hexane: ethyl acetate (8:2, 
v/v) was optimized, and it provided good resolution for a-terpinyl acetate. The chromatographic conditions of the developed method such as saturation time, $R_{f}$ value, spraying reagent, and scanning wavelength were $10 \mathrm{~min}, 0.64$, anisaldehyde-sulfuric acid and $665 \mathrm{~nm}$, respectively. These conditions were reliable, precise and good for quantification of $\alpha$ terpinyl acetate.

LOD and LOQ values revealed the suitable sensitivity of the developed method. Recovery of a-terpinyl acetate was nearly 100 , indicating that there was no interference in the analysis by the other compounds present in the essential oil, which is evidence of the accuracy of the developed method [16]. The peak area RSD (\%) did not exceed two percent $(<2 \%)$, both in the intra-day and inter-day observations, showing the high precision of developed method [17].

The range of relative standard deviation (\% RSD) obtained for robustness of the method observed after small changes in the TLC process indicates the robustness of the method [18]. The HPTLC method was used to calculate the amount of $\alpha$ terpinyl acetate present in the essential oils of the selected varieties of $E$. cardamomum, and the results indicated that the essential oil of Valley green had the highest content of $\alpha$ terpinyl acetate.

In the present study, the essential oil of Valley green fruits had the highest antioxidant potential, when compared to the other oils, with respect to DPPH and ABTS radical scavenging potential. The ABTS free radical has been broadly used to assess the antioxidant ability of essential oils, and it is more reactive than DPPH radical [19]. The antioxidant effect of the essential oils was highly associated with the contents of the bioactive constituent $\alpha$-terpinyl acetate.

The reagent, 2,2-diphenyl-1-picrylhydrazyl (DPPH) is a stable, reliable and popular radical used for testing the antioxidant effects of plant extracts or essential oils [20]. The violet colour of the DPPH radical changes to yellow after receiving a free electron. Compounds which undergo this colour transformation are considered as antioxidants. The findings in the present study are in agreement with those obtained in a previous study, where it was reported that different cultivars of $E$. cardamomum exerted different antioxidant properties [21]. The reducing assay method also revealed the high antioxidant potential of the Valley green variety of $E$. cardamomum. The antioxidant property of a-terpinyl acetate has also been reported by other investigators [5,22].

\section{CONCLUSION}

A simple, rapid, specific, accurate, and precise HPTLC method for the determination of $\alpha$ terpinyl acetate in the essential oils of cardamom has been successfully developed. The developed method is sensitive, and is suitable for use in quality control. Based on the method, the content of $\alpha$-terpinyl acetate in the essential is high for fruits of Valley green variety. Since a-terpinyl acetate is a principal component of the $E$. cardamomum essential oil, it may be responsible for the high antioxidant effect of Valley green oil. The findings of the current study may provide a basis for accurate determination of a-terpinyl acetate in other plant species.

\section{DECLARATIONS}

\section{Acknowledgement}

AA thanks Mr Ashutosh Gautam, Scientist B at Crop Improvement section in Indian Cardamom Research Institute (ICRI) spice board, Myladumpara, Idukki, Kerala for the providing the cardamom samples. Logistical supports of Biotechnology Department, School of Engineering, Sharda University is highly acknowledged.

\section{Conflict of interest}

No conflict of interest is associated with this work.

\section{Contribution of authors}

We declare that this work was done by the authors named in this article and all liabilities pertaining to claims relating to the content of this article will be borne by the authors.

\section{Open Access}

This is an Open Access article that uses a funding model which does not charge readers or their institutions for access and distributed under the terms of the Creative Commons Attribution License (http://creativecommons.org/licenses/by/ 4.0) and the Budapest Open Access Initiative (http://www.budapestopenaccessinitiative.org/rea d), which permit unrestricted use, distribution, and reproduction in any medium, provided the original work is properly credited.

\section{REFERENCES}

1. Nadiya F, Anjali N, Thomas J, Gangaprasad A, Sabu KK. 
Transcriptome profiling of Elettaria cardamomum (L.) Maton (small cardamom). Genom Data 2017; 11: 102103.

2. Elgayyar M, Draughon FA, Golden DA, Mount JR. Antimicrobial activity of essential oils from plants against selected pathogenic and saprophytic microorganisms. J Food Prot 2001; 64: 1019-1024.

3. Ahmed AS, Ahmed Q, Saxena AK, Jamal P. Evaluation of in vitro antidiabetic and antioxidant characterizations of Elettaria cardamomum (L.) Maton (Zingiberaceae), Piper cubeba L. f. (Piperaceae), and Plumeria rubra $L$. (Apocynaceae). Pak J Pharm Sci 2017; 30: 113-126.

4. Ankegowda SJ, Biju CN, Jayashree E, Prasath D, Praveena $R$, Senthil Kumar CM. Srinivasan $V$. Cardamom. ICAR-Indian Institute of Spices Research, Kozhikode, 2015; 1-26.

5. Amma KPP, Sasidharan I, Sreekumar MM, Sumathykutty MA, Arumughan C. Total Antioxidant Capacity and Change in Phytochemicals of Four Major Varieties of Cardamom Oils During Decortication. Int J Food Prop 2015; 6: 1317-1325.

6. Vijayan $A K$, Pradipkumar $K$, Remashree AB. Small Cardamom Production Technology and Future Prospects. Int J Agric Sci 2018; 10: 6943-6948.

7. Marongiu B, Piras A, Porcedda S. Comparative analysis of the oil and supercritical $\mathrm{CO}_{2}$ extract of Elettaria cardamomum (L.) Maton. J Agric Food Chem 2004; 52(20): 6278-6782.

8. Abdullah, Asghar A, Butt MS, Shahid M, Huang $Q$. Evaluating the antimicrobial potential of green cardamom essential oil focusing on quorum sensing inhibition of Chromobacterium violaceum. J Food Sci Technol 2017; 54(8): 2306-2315.

9. Singh $G$, Kiran $S$, Marimuthu $P$, Isidorov V, Vinogorova $V$. Antioxidant and antimicrobial activities of essential oil and various oleoresins of Elettaria cardamomum (seeds and pods). J Sci Food Agric 2008; 88: 280-289.

10. Attimarad M, Ahmed KKM, Aldhubaib BE, Harsha S. High-performance thin layer chromatography: $A$ powerful analytical technique in pharmaceutical drug discovery. Pharm Methods 2011; 2: 71-75.

11. Taghvaei M, Jafari SM. Application and stability of natural antioxidants in edible oils in order to substitute synthetic additives. J Food Sci Technol 2013; 52(3): 1272-1282.
12. ICH. Harmonised Tripartite Guidelines; Validation of Analytical Procedures; Text and Methodology; Q2 (R1); Geneva 2005; 1-8.

13. Bozin B, Mimica-Dukic N, Simin N, Anackov G. Characterization of the volatile composition of essential oils of some lamiaceae spices and the antimicrobial and antioxidant activities of the entire oils. J Agric Food Chem 2006; 54: 1822-1828.

14. Gulcin I, Elmastas M, Hassan $Y$, Aboul-Enein HY. Antioxidant activity of clove oil - $A$ powerful antioxidant source. Arab J Chem 2012; 5: 489-499.

15. Han F, Ma G, Yang M, Yan L, Xiong W, Shu J, Zhoa Z, $\mathrm{Xu} \mathrm{H}$. Chemical composition and antioxidant activities of essential oils from different parts of the oregano. $J$ Zhejiang Univ Sci B 2017; 8: 79-84.

16. Kamboj A, Sauja AK, Development of validated HPTLC method for quantification of stigmasterol from leaf and stem of Bryophyllum pinnatum. Arab J Chem 2017; 10(2): S2644-S2650.

17. Alam A, Majumdar RS. Antioxidant activity of essential oil of three cultivars of Amomum subulatum and standardization of high performance thin layer chromatography (HPTLC) method for the estimation of 1,8 ciniole. Afr J Biotech 2018; 17.36; 1129-1137.

18. Alam P, Yusufoglu $H$, Alam A. HPTLC densitometric method for analysis of thymoquinone in Nigella sativa extracts and marketed formulations. Asian Pac J Trop Dis 2013; 3(6): 467-471.

19. Sowndhararajan K, Kang SC. Free radical scavenging activity from different extracts of leaves of Bauhinia vahlii Wight \& Arn. Saudi J Biol Sci 2013; 20: 319-325.

20. Kaviarasan S, Naik GH, Gangabhagirathi R, Anuradha $C V$, Priyadarsiniln KI. In vitro studies on antiradical and antioxidant activities of fenugreek (Trigonella foenum graecum) seeds. Food Chem 2007; 103: 31-37.

21. Saeed A, Sultana B, Anwar F, Mushtaq M, Alkharfy KM, Gilani AH. Antioxidant and Antimutagenic Potential of Seeds and Pods of Green Cardamom (Elettaria cardamomum). Int J Pharmacol 2014; 10: 461-469.

22. Cutillas IA, Carrasco A, Martinez-Gutierrez R, Tomas V, Tudela J. Composition and Antioxidant, Antienzymatic and Antimicrobial Activities of Volatile Molecules from Spanish Salvia lavandulifolia (Vahl) Essential Oils. Molecules 2017; 22: 1382 